\title{
Prevalence of Claw Disorders in Dutch Dairy Cows Exposed to Several Floor Systems
}

\author{
J. G. C. J. Somers, ${ }^{\star} †$ K. Frankena,‡ E. N. Noordhuizen-Stassen, $†$ and J. H. M. Metz* \\ *Institute of Agricultural and Environmental Engineering (IMAG), Mansholtlaan 10-12, PO Box 43, \\ 6700 AA Wageningen, The Netherlands \\ †Department of Farm Animal Health, Faculty of Veterinary Medicine, Utrecht University, \\ Yalelaan 7, PO Box 80151, 3508 TD Utrecht, The Netherlands \\ $\ddagger W a g e n i n g e n$ Institute of Animal Sciences, Wageningen University, Marijkeweg 40, \\ PO Box 338, $6700 \mathrm{AH}$ Wageningen, The Netherlands
}

\begin{abstract}
Claw health was examined in an observational study on Dutch dairy farms with either a slatted floor (SL), slatted floor with manure scraper (SL-SCR), solid concrete floor (SCF), a straw yard (SY), or a zero-grazing feeding system (ZG). Hooves of cows' hind legs were examined for the presence and severity of claw disorders during hoof trimming events at the end of the pasture (P-study) and housing period (H-study). The number of cows in each study was 3078 (49 herds) and 3190 (47 herds), respectively. Due to a different hoof trimming strategy, data collected during both observation periods in SY herds (638 cows; 16 herds) were combined. Cows in straw yards (SY) had by far the lowest numbers of claw disorders. Over $80 \%$ of cows exposed to concrete flooring had at least one claw disorder at the time of observation, whereas on SY surfaces, this percentage was between 55 and 60 . Cows on SLSCR were less frequently affected by interdigital dermatitis/heel erosion (IDHE) and digital dermatitis (DD) than cows on SL (reference floor system). Little difference in claw health was found between SF and SL. The $\mathrm{ZG}$ cows were at higher risk $(\mathrm{OR}>2)$ for most claw disorders in the P-study, whereas in the H-study, ZG cows showed less IDHE, sole hemorrhage, and sole ulcer. All herds on concrete flooring (SL, SL-SCR, SCF, $\mathrm{ZG}$ ) were infected by DD, resulting in an average cow level prevalence of $30 \%$. This indicates that the level of DD infection has increased considerably over the last $10 \mathrm{yr}$ in The Netherlands.
\end{abstract}

(Key words: claw disorder, epidemiology, floor system, lameness)

Abbreviation key: DD = digital dermatitis, H-study = housing study, HYP = interdigital hyperplasia, IDHE

Received: October 10, 2002.

Accepted: January 3, 2003.

Corresponding author: J. G. C. J. Somers; e-mail: joan.somers @wur.nl.
$=$ interdigital dermatitis/heel erosion, $\mathbf{I P}=$ interdigital phlegmon, $\mathbf{O R}=$ odds ratio, $\mathbf{P}$-study = pasture study, $\mathbf{P} / \mathbf{H}$-study = merged pasture and housing study, SCF = solid concrete floor, $\mathbf{S H}=$ sole hemorrhages, $\mathbf{S L}=$ slatted floor, SL-SCR = slatted floor with manure scraper, SOC $=$ solar contusion, $\mathbf{S U L}=$ sole ulcer, $\mathbf{S Y}$ = straw yard, $\mathbf{W L A}=$ white line abscess, $\mathbf{W L S}=$ white line separation, $\mathbf{Z G}=$ zero-grazing.

\section{INTRODUCTION}

Claw disorders are frequently reported in dairy cattle all over the world. Weaver (2000) reported that diseases of the claw account for about $90 \%$ of all lameness incidents. Claw disorders are distinguished at clinical level (i.e., being lame) and at subclinical level (i.e., digital disorders recognizable at hoof trimming). Disturbed claw health is an unequivocal source of suffering for the cows (Webster, 1995), because the disorder is usually long term and painful (Alban, 1995). The Dutch Advisory Board for Animal Affairs (RDA) has considered actual levels of clinical (30\% cow cases per year) and subclinical claw disorders in The Netherlands as unacceptable from an animal welfare point of view (RDA, 1996). In other countries, the prevalent lameness rates are also stated as not acceptable, and they give rise to a growing concern about animal welfare (Farm Animal Welfare Council, 1997).

Lameness is characterized as a multifactorial condition. It is the result of an interaction between housing design, farm management, nutrition, and animal characteristics (Clarkson et al., 1993). Because lameness incidence is higher in the winter period when cows are housed indoors compared to periods when animals have access to pasture (Leaver, 1988; Faye and Lescourret, 1989; Webster, 1995), it is obvious that the housing environment has a large impact. Floors are hypothesized as a crucial factor in locomotion and claw health (Albright, 1995).

Several studies have evaluated the incidence of lameness under different housing and flooring circum- 
stances. Concrete flooring, characterized as abrasive and unyielding, and uncomfortable stalls have been associated with a higher incidence of lameness (Vokey et al., 2001). A direct relationship between housing conditions and several digital disorders has been shown experimentally (Bergsten, 1995; Vermunt and Greenough, 1996). Frequently, it has been reported that loose cubicle housing increases the incidence of lameness compared with tied housing (Maton, 1987; Thysen, 1987; Faye and Lescourret, 1989; Clarkson et al., 1993; Hultgren, 2002). Epidemiological studies in The Netherlands (Frankena et al., 1991) and in France (Faye and Lescourret, 1989) revealed that claw health was worse during indoor cubicle housing than during pasturing. Following those findings, the effect of all year round indoor cattle housing on hoof health was investigated in zero-grazing herds. Several claw disorders appeared to be more prevalent under zero-grazing circumstances in Dutch dairy farms (Smits et al., 1992). Zerograzed cattle in small-scale Kenyan herds had a three times higher risk for a lameness event than cattle that had access to pastures (Gitau et al., 1996). These lameness surveys underline the seriousness of hoof problems resulting from modern dairy housing facilities.

Given the incidence of claw and lameness problems on traditional concrete flooring, the possibilities of softer, more natural flooring properties in livestock housing have also been investigated. Beneficial effects of deep litter straw-based systems have been suggested from an animal welfare point of view (ADAS, 1994; Singh et al., 1994). Indeed, better claw health was found in beef cattle (Maton, 1987; Murphy et al., 1987) and in dairy calves (Frankena et al., 1993) kept in straw yards rather than on slatted floors. But to what extent the same applies for dairy cattle housed in straw yard systems is unclear.

In a recent study aimed at welfare assessment, Fregonesi (1999) showed that dairy cows had a clear preference for standing on a soft surface such as that in straw yard systems rather than on a concrete floor, as in cubicle housing systems. In contrast, no significant differences in hoof dimensions, locomotion score, or clinical lameness were found between those two housing systems (Fregonesi and Leaver, 2000). Hughes et al. (1997) reported a significant reduction in incidence and prevalence of lameness in a three herd study after changing from cubicle housing to straw yards. Both positive (reduction in sole and white line hemorrhages) and negative effects (increase in heel horn erosion) on claw health were found in an experimental study in heifers transferred from cubicle yards into straw yards (Livesey et al., 1998).

The design of livestock housing widely differs in many parts over the world. Cubicle housing system with a concrete floor is the predominant housing type for dairy cattle in The Netherlands. Approximately $90 \%$ of the dairy cows are kept in cubicle houses with a slatted floor (Braam and Swierstra, 1997), while about 10\% are kept on solid concrete floors with scraper. A very small percentage of cows are housed in tie stalls or straw yard systems. In recent years, two trends are apparent in modern Dutch dairy production. First, through the introduction of robotic milking, more stringent manure legislation, and cost price reduction, an increasing number of dairy cattle are being housed indoors throughout the year. Second, a more extensive organic farming system is developing in which cows are often housed in a straw yard.

Lowering the prevalence of claw disorders and lameness incidents in current housing systems requires more insight into the floor factors that are involved. The urgency of research is increased by the mentioned developments in housing intensity and design. The objectives of this study are (1) to investigate prevalence and severity of claw disorders at subclinical level in a large sample of the Dutch dairy cattle population and (2) to assess the effect of various flooring systems on that prevalence.

\section{MATERIALS AND METHODS}

\section{Study Design and Population}

The study can be characterized as a cross-sectional observational study for prevalence estimation (Thrusfield, 1986). Claw health was recorded on 86 dairy farms. Observations at hoof trimming events occurred within the specific changeover periods between pasturing and housing (Autumn 1999) and vice versa (Spring 2000). Only cows that were at least $50 \mathrm{~d}$ at pasture at the time of hoof trimming, and not longer than $15 \mathrm{~d}$ housed indoors were included in the pasture study, (P. study). Cows included in the housing study, (H-study), were housed for at least $50 \mathrm{~d}$ indoors, and thereafter no longer than $15 \mathrm{~d}$ at pasture during daytime. Due to a different hoof trimming strategy in most straw yard (SY) herds, it was decided to place all data collected in SY herds within both observation periods and analyze them together in a merged pasture and housing study (P/H-study).

Herds involved in the study were selected from lists of clients of Agricultural Consultancy Service (DLV), Agricultural Farm Service (ABV), and local professional hoof trimmers. Farms with either a slatted floor (SL), slatted floor with manure scraper (SL-SCR), solid concrete floor (SCF, always with manure scraper), or a SY loose housing system, with or without a small concrete walking area behind the feeding rack, were included. In addition to the floor system, other selection criteria 
were: herd size $>25$ cows, herd milk yield $>7000 \mathrm{~kg} /$ cow/yr, member of the Dutch herdbook milk recording system (Royal Dutch Dairy Syndicate, NRS), and routine herd hoof trimming twice a year. Herds kept on concrete floor systems (SL, SL-SCR, SCF) were primarily pure Holstein and Holstein crossbreeds. In SY herds, besides Holstein breeds, other breeds were found, such as Dutch Friesian, Jersey, and Mont Beliardes.

Most herds in this study had access to pasture in the summer season. Some farms $(\mathrm{n}=13)$, however, had housed their cows indoors all year round. These zerograzing (ZG) herds were analyzed separately as a distinctive farming system. Ten ZG herds had a SL, two had a SCF, and one had a SL-SCR. In general, SY farms are characterized by a less intensive management than conventional dairy farms, resulting in herd milk yield $<7000 \mathrm{~kg} /$ cow per year in nine out of the 16 SY study farms, and no herd hoof trimming has been done routinely twice a year in most study SY herds (except for one herd); eight SY farms trimmed once a year, while seven other SY farms had not trimmed their herds for at least 5 yr. Although short of the selection criteria, the SY farms were included in the study because of their interesting floor system from a claw health point of view.

Claw health records of 3078 cows (49 herds), 3190 cows (47 herds), and 638 cows (16 herds) in the P-, Hand $\mathrm{P} / \mathrm{H}$-study, respectively, were used for descriptive analysis. The distribution of $\mathrm{P}-, \mathrm{H}-$, and $\mathrm{P} / \mathrm{H}$-study population within each floor system, as well as distributions of parity, stage of lactation and 305-d herd production are shown in Table 1. Herd level and individual level milking information were obtained from computerized milking records

\section{Diagnoses}

All claw lesions were recorded during routine herd trimming visits. Professional hoof trimmers conducted the trimmings. The first author made the claw observations in assistance with a group of animal science students. These students were trained in diagnosing claw disorders by studying photographs of affected claws and through live demonstration by a hoof-trimming expert employed by the Utrecht Faculty of Veterinary Medicine. The first author checked at several times during this study to determine whether claw examinations done by the students agreed with his diagnostic opinion, regarded as standard in this study.

Hooves of hind legs of each animal were examined for the presence and severance of claw disorders. Interdigital dermatitis (ID) and its resulting symptom heel horn erosion (HE) were diagnosed together as IDHE. IDHE was rated on a scale of 0 to 3 , based on the

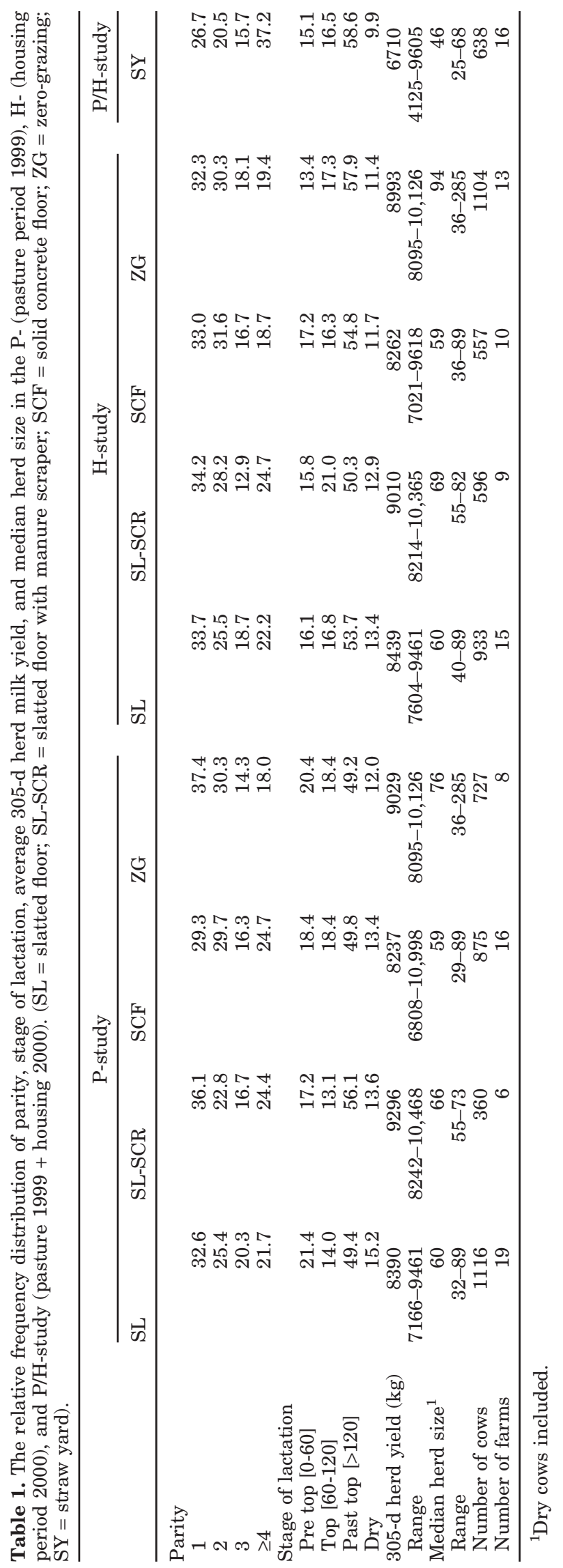


definitions of Peterse (1980): 0, no signs; 1, slight pock marking and/or superficial horn defects in the axial surface of the bulb; 2, some big fissures or grooves in the horn of the bulb and/or sole, not extending to the corium; 3, disappearance of heel horn and/or deep defects in the horn of bulb or sole, extending to the corium.

Diagnosis of lesions of digital dermatitis (DD) was based on the classification developed by Döpfer (1994). Digital dermatitis is synonymous with PPD (papillomatous digital dermatitis), a name recently introduced in North America (Read and Walker, 1998). In our study, the presence of active, classical ulcerative lesions, characterized by a red, granular, strawberry-like surface (Read et al., 1992) and classified by Döpfer as disease stage M1 and M2, were recorded. Other clinical signs associated with M1 and M2 were pain reactivity after palpation, foul odor, and swelling at the affected site. M1 (= DD grade 1) is defined as an early stage of DD with a circumscribed granulomatous area, 0.5 to 2 $\mathrm{cm}$ in diameter. A circumscribed classical ulceration area more than $2 \mathrm{~cm}$ in diameter, and two or more (smaller) affected spots within the same claw have been classified as M2 (= DD grade 2).

In the case of scoring sole hemorrhages (SH), the surface of each claw was divided into six zones according to recommendations established on the VIth Symposium on Diseases of the Ruminant Digit (Liverpool, 1990). Zones 1, 2, and 3 made up the white line, zones 4 and 5 the sole, and zone 6 the heel. The severity of SH was evaluated for each of the six zones by density and extent of the hemorrhage, based on the method proposed by Greenough and Vermunt (1991): 0, no or slight yellow discoloration; 1, slight red discoloration, occurring in stripes or small spots; 2 , moderate hemorrhage; 3 , severe hemorrhage; 4 , exposed corium/sole ulcer.

Ulcerations in zones 4 (sole ulcer), 5 (toe ulcer), and 6 (heel ulcer) were combined and reclassified as sole ulcer (SUL). An earlier stage of ulceration, when the corium was not exposed, was scored as solar contusion (SOC). An early stage of white line disease (zones 1, 2, and 3) was characterized as white line separation (WLS). White line abscess (WLA) was defined as an advanced stage of white line disease, when a white line separation has progressed to the level of the corium resulting in abscess formation. The disorders interdigital hyperplasia (HYP) and interdigital phlegmon (IP) were diagnosed as being present (1) or not (0).

\section{Data Analyses}

All data analyses were performed using the statistical packages SAS (1996) and SPSS (2002). Claw health was assessed in terms of prevalence rates for all claw disorders (except IP). Prevalence rate was calculated as the proportion of animals with the outcome of a given claw disorder. For each claw disorder, the highest score within any hind claw was set as the final outcome for the cow. In addition to cow level prevalence, herd prevalence rates were calculated for IDHE, DD, and SH (as being most frequent disorders).

Associations between floor system and the occurrence of a specific claw disorder were estimated using a binomial distribution and a logistic link function (logistic regression) in PROC GENMOD of SAS. Polytomous variables (e.g., IDHE, DD, SH) were reduced into dichotomous outcomes (i.e., a cow was positive or negative for a certain claw disorder at the time of observation). When analyzing IDHE, we distinguished slight, superficial IDHE from serious and severe IDHE lesions. A cow was scored IDHE-positive when she had IDHE lesions grade 2 or 3; superficial IDHE (grade 1) was assumed as IDHE-negative. Scores for DD and SH were dichotomized as follows: DD grade 1 and 2, and $\mathrm{SH}$ grade $1,2,3$, and 4 were assumed as DD- and SHpositive, respectively. Cows within one herd are all exposed to the same environmental circumstances and, subsequently, cannot be considered as independent units in the analysis. Therefore, the standard errors of the regression coefficients were scaled by a factor equal to the square root of the reciprocal of the Pearson chisquare, which takes the dependence into account and will result in increased $P$ values.

Odds ratios (OR) were calculated, indicating the estimated risk for the outcome of a claw disorder at a certain floor system, relative to the estimated risk at the reference floor system $(\mathrm{OR}=1)$. SL was set as reference floor system, since it is the predominant floor system for dairy cattle in The Netherlands. Associated $P$ values were calculated to test whether or not odds of claw disorders differ significantly between SL and other floor systems (SL-SCR, SCF, ZG, and SY). The differences in mean herd prevalence rates between the $\mathrm{P}-, \mathrm{H}-$, and $\mathrm{P} / \mathrm{H}$-study were tested using the Kruskal-Wallis oneway ANOVA on ranks $(\alpha=0.05)$. The Mann-Whitney $\mathrm{U}$ test was performed to analyze differences in prevalence rates of ZG cows in the H-study. The Wilcoxon Signed Ranks test was used to examine seasonal differences in prevalence rates of ZG cows that were present in both the P- and $\mathrm{H}$-study. For all analyses, differences were considered significant when $P \leq 0.05$.

\section{RESULTS AND DISCUSSION}

\section{Study Population}

The median herd size in the $\mathrm{P}$ - and $\mathrm{H}$-study populations (60 and 64 cows, respectively; dry cows included) was higher than the average herd size of dairy farms 
participating in the Dutch milk recording system (51 cows, CBS, 2000). In both the P- and H-study, ZG herds showed highest median herd size: 76 and 94 cows, respectively. The average 305-d herd milk yield in our study farms (8555 and $8664 \mathrm{~kg}$ in the $\mathrm{P}$ - and $\mathrm{H}$-study, respectively) was also higher than that in the Dutch milk recording population (8222 kg; LEI and CBS, 2001). The average 305-d herd milk yield was highest in SL-SCR herds: 9296 and $9010 \mathrm{~kg}$ in the P- and Hstudy, respectively. Although numerous authors have associated herd size and milk yield with higher overall incidence of lameness (Gröhn et al., 1992; Alban, 1995) and higher levels of claw disorders, such as DD (Wells et al., 1995, 1999) and IDHE (Frankena et al., 1993), it can be argued whether the small deviation in herd characteristics between our study population and those in an average Dutch dairy herd actually biased our prevalence rates. We believe that, because of the largescale study population in both the $\mathrm{P}$ - and $\mathrm{H}$-study and the well-defined selection criteria, farms included in the current study make up a good representation of common Dutch dairy farms, and subsequently, our findings reflect the current situation with respect to claw health in dairy cows housed in loose, cubicle housing systems in The Netherlands.

In SY herds, both median herd size (46 cows) and average $305-d$ herd yield $(6710 \mathrm{~kg})$ were lower than those in the milk recording population. As mentioned before, high-milk-yield dairy cows are at higher risk for lameness events at both clinical and sublinical level. In addition to lower herd size and herd milk yield, SY herds have also a lower percentage of Holstein-Friesian cattle in favor of less lameness-susceptible breeds such as Mont-Beliardes and Jersey (Peterse, 1985). Besides the possible benefit of a soft floor surface, lower prevalence rates in SY herds may be partially explained by bias due to such negatively associated factors.

\section{Cow Level Prevalence}

Claw disorders per cow. The majority of cows had claw disorders at subclinical level. Within cows exposed to concrete flooring (SL, SL-SCR, SCF, and ZG), 78\% in the P-study and $81 \%$ in the H-study had at least one claw disorder (based on dichotomous outcomes, i.e., IDHE grade $1=$ IDHE-negative) at the time of hoof trimming (Figure 1). Many cows showed one or two claw disorders in both the $\mathrm{P}$ - (36.2 and $26.2 \%$, respectively) and $\mathrm{H}$-study (36.8 and $28.7 \%$, respectively). Approximately $4 \%$ of the cows exposed to concrete flooring in the P-study and $2.9 \%$ in the H-study had four or more claw disorders. Compared with concrete flooring, the number of claw disorders per cow was considerably lower on SY farms where $42.5 \%$ of the cows were free

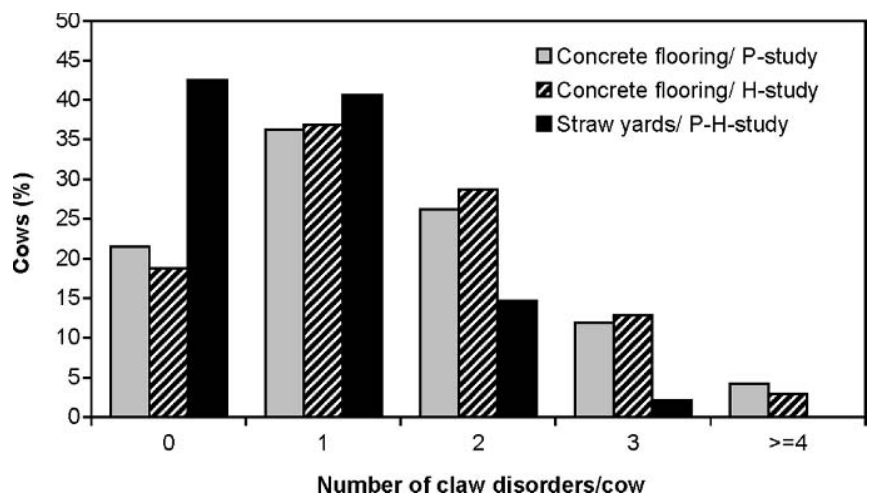

Figure 1. Distribution of the number of claw disorders per cow (based on binary data, i.e., IDHE grade 1 = IDHE-negative) in Dutch dairy cows exposed to concrete floor systems in the P- (pasture period 1999 ) and H-study (housing period 2000), and exposed to straw yards in the $\mathrm{P} / \mathrm{H}$-study (pasture 1999 + housing 2000).

of any claw disorder at the time of observation. About $40 \%$ of the SY cows showed one claw disorder, whereas the remainder had two (14.7\%) or three $(2.2 \%)$ claw disorders.

Seasonal influence. Table 2 shows the original ordinally scored cow level prevalence rates for IDHE, DD, and SH observed on different floor systems. IDHE was the most frequent disorder, but many cows were just mildly affected (grade 1; on average 32.7 and $41.4 \%$ in the $\mathrm{P}$ - and $\mathrm{H}$-study, respectively). This agreed with findings in three earlier Dutch epidemiological studies (Peterse, 1980; Frankena et al., 1991; Smits et al., 1992). Moreover, we found that IDHE lesions were more prevalent and more severe in the housing period than during grazing, which confirms that IDHE infection has a seasonal pattern, and the degree of affection is highest at the end of the housing period, as decribed earlier (Peterse, 1980, 1987; Frankena et al., 1991).

A beneficial effect of grazing on the prevalence of DD lesions, as suggested by Frankena et al. (1991), could not be determined in our study. Within cows exposed to concrete flooring with grazing facilities (SL, SL-SCR, and SCF), the level of DD infection was almost similar in the P- and H-study (on average 27.7 and 27.9\%, respectively). Furthermore, prevalence rates of DD have increased considerably in comparison with the situation 10 yr ago reported by Frankena et al. (1991); then, 8.1 and $13.8 \%$ of the cows in the study population were affected by DD at the end of the pasture and housing season, respectively.

Differences in prevalence rates of claw disorders in the $\mathrm{P}-, \mathrm{H}-$, and $\mathrm{P} / \mathrm{H}$-study might have its origin in several causes. First, in some marginal cases, differences in the interpretation of presence and severity of a claw disorder may have occurred due to inter- and intra- 
Table 2. Cow prevalence per severity of lesion of interdigital dermatitis/heel erosion (IDHE), dermatitis digitalis (DD), and sole hemorrhages (SH) in dairy cows exposed to concrete floor systems in the P- (pasture period 1999) and H-study (housing period 2000), and in straw yards (SY) in the P/H-study (pasture 1999 + housing 2000). (SL = slatted floor; SL-SCR = slatted floor with manure scraper; $\mathrm{SCF}=$ solid concrete floor; $\mathrm{ZG}$ = zero-grazing).

\begin{tabular}{|c|c|c|c|c|c|c|c|c|c|}
\hline \multirow[b]{2}{*}{ Diagnosis } & \multicolumn{4}{|c|}{ P-study } & \multicolumn{4}{|c|}{ H-study } & \multirow{2}{*}{$\frac{\mathrm{P} / \mathrm{H} \text {-study }}{\mathrm{SY}}$} \\
\hline & SL & SL-SCR & SCF & ZG & SL & SL-SCR & SCF & $\mathrm{ZG}$ & \\
\hline IDHE grade 0 & 44.6 & 52.5 & 35.5 & 31.8 & 7.3 & 19.8 & 10.2 & 16.1 & 29.6 \\
\hline grade 1 & 34.7 & 32.8 & 34.1 & 27.9 & 42.0 & 44.3 & 37.4 & 41.2 & 57.1 \\
\hline grade 2 & 18.5 & 13.1 & 26.2 & 29.9 & 45.3 & 34.1 & 48.1 & 40.4 & 13.3 \\
\hline grade 3 & 2.2 & 1.7 & 4.2 & 10.5 & 5.4 & 1.8 & 4.3 & 2.3 & 0.0 \\
\hline DD grade 0 & 70.3 & 72.5 & 74.6 & 51.0 & 69.3 & 79.9 & 68.8 & 69.3 & 96.1 \\
\hline grade 1 & 17.7 & 17.5 & 12.2 & 17.5 & 13.9 & 10.2 & 10.0 & 10.0 & 2.5 \\
\hline grade 2 & 11.9 & 10.0 & 13.1 & 31.5 & 16.8 & 9.9 & 21.2 & 20.7 & 1.4 \\
\hline SH grade 0 & 54.9 & 52.2 & 53.0 & 36.7 & 52.3 & 44.3 & 54.8 & 68.8 & 75.7 \\
\hline grade 1 & 32.9 & 34.7 & 34.2 & 40.6 & 29.4 & 33.4 & 20.1 & 21.5 & 16.1 \\
\hline grade 2 & 8.9 & 10.6 & 10.1 & 16.2 & 14.5 & 16.8 & 17.8 & 8.1 & 6.7 \\
\hline grade 3 & 2.9 & 2.5 & 2.5 & 5.4 & 3.7 & 4.3 & 6.8 & 1.4 & 0.9 \\
\hline grade 4 & 0.5 & 0.0 & 0.2 & 1.1 & 0.1 & 1.2 & 0.5 & 0.2 & 0.5 \\
\hline
\end{tabular}

observer variation. For example, in scoring the severity of IDHE, DD, and $\mathrm{SH}$, when distinguishing between a slight (grade 1), or more serious lesion (grade 2 or higher). The borderline between these two disease stages can be doubtful in some cases. In common, however, this was considered of minor importance because most claw disorders and symptoms are well recognizable, observers were specially trained, and observers' records were regularly checked during the observation period. Second, the time period between two consecutive herd-trimming events was not taken into account in the present analysis. The importance of hoof trimming interval when interpreting claw health records has been recognized by Enevoldsen and Gröhn (1991). Hoof trimming, as part of the farm management, can be used either as a preventive or curative tool. If study herds have brought forward their date of herd trimming in order to prevent serious claw problems, this might result in an underestimation of the prevalence rates for certain claw lesions. Other farmers, however, may have been less attentive to their cattle's claw health, allowing a longer time period between two herd trimmings, i.e., an overestimation. Third, farms included in the P-study were not necessarily the same as those in the $\mathrm{H}$-study. In total, 35 farms were included in both the $\mathrm{P}$ - and $\mathrm{H}$ study; 26 farms were included once, either in the P- or $\mathrm{H}$-study. (Some farms could not be visited twice because herd trimming coincided on several farms; other farms were not included in the $\mathrm{P}$ - or $\mathrm{H}$-study analysis because they exceeded the definitions of either pasture or housing period). Finally, the level of exposure to some risk factors for claw disorders may have varied between pasture and housing period, resulting in differences in prevalence rates. An inventory of potential cow and environmental risk factors was also part of the present study. Results of the risk analyses will be reported separately.

\section{Herd Level Prevalence}

IDHE. Figure 2 shows the distribution of herd prevalence rates for serious IDHE among herds with concrete flooring and in SY herds. All herds with concrete flooring in the $\mathrm{P}$ - and $\mathrm{H}$-study had cows that showed serious IDHE lesions (grades 2 and 3). Herd prevalence ranged between 3 and $92 \%$ in the P-study (median $=24.2 \%$ ), and between 2 and $93 \%$ in the H-study (median = $48.8 \%$ ), whereas in SY herds this range was between 0 and $49 \%$ (median $=5.7 \%$ ). The Kruskal-Wallis Multiple Comparison Z-Value test $(\alpha=0.05)$ showed that the differences in IDHE herd prevalence rates were significant between the P- and $\mathrm{H}$-study, as well as between cows on concrete flooring in the H-study and cows in SY herds in the $\mathrm{P} / \mathrm{H}$-study.

DD. Mean herd prevalence rates for DD varied greatly (Figure 3), ranging between 2 and $73 \%$ in the P-study (median $=27.6 \%$ ) and 1 and $65 \%$ in the $\mathrm{H}$ study (median $=24.4 \%)$. These numbers suggest that the level of DD infection in The Netherlands has become worse over the last decade. In a similar observational field study under 59 Dutch dairies, Frankena et al. (1991) reported that in the majority of herds, $<15 \%$ of the cows were affected by DD. Moreover, since then the disease has become more widespread among dairy herds. Approximately 19 and 7\% of the herds studied by Frankena et al. (1991) were not affected by DD at the end of the pasture and housing period, respectively. In our study, however, none of the herds in the $\mathrm{P}$ - and $\mathrm{H}$-study were free from DD lesions. A marked contrast was seen in SY farms, where almost 65\% ( $\mathrm{n}=10)$ of 


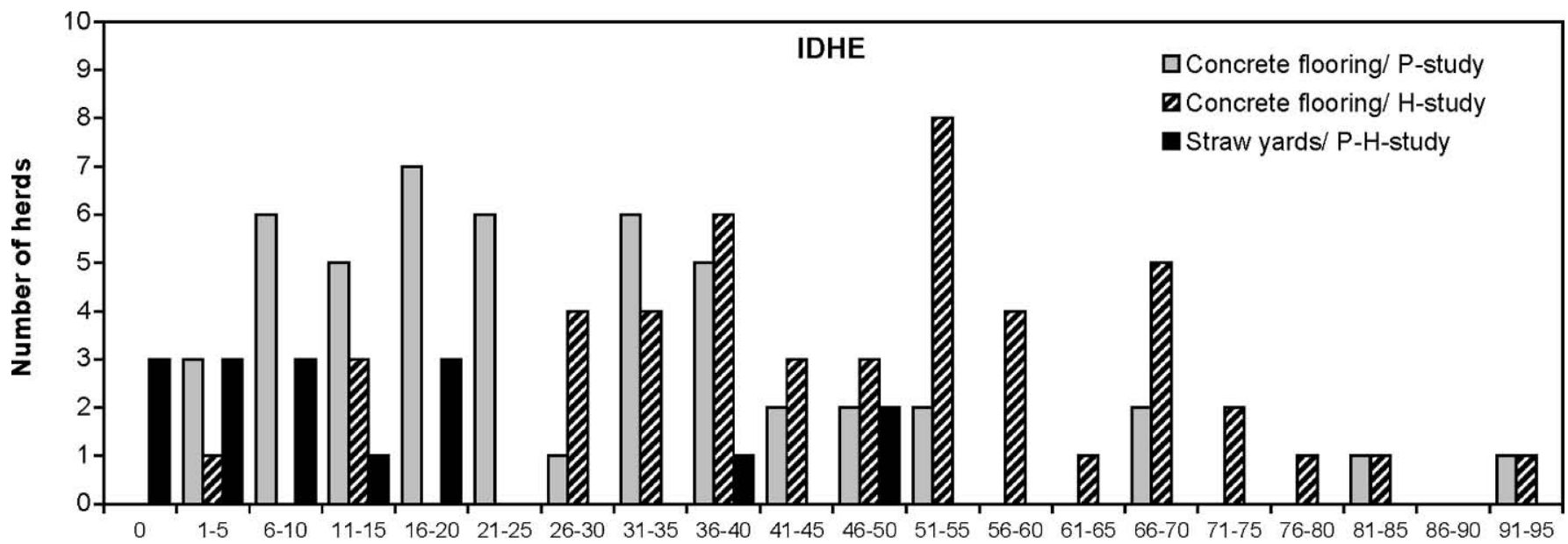

Herd prevalence level (\%)

Figure 2. Distribution of herd prevalence rates for serious interdigital dermatitis/heel erosion (IDHE) in Dutch dairy cows exposed to concrete flooring in the P- (pasture period 1999; $\mathrm{n}=49$ farms) and $\mathrm{H}$-study (housing period 2000; $\mathrm{n}=47$ farms), and exposed to straw yards in the $\mathrm{P} / \mathrm{H}$-study (pasture $1999+$ housing $2000 ; \mathrm{n}=16$ farms).

the herds were completely free of DD (median $=0.0 \%$; range $=0$ to $29 \%$ ). Differences in mean DD herd prevalence rates between SY farms and farms having concrete flooring in either the $\mathrm{P}$ - or $\mathrm{H}$-study were tested as significant (Kruskal-Wallis test).

$\boldsymbol{S H}$. Herd prevalence rates for $\mathrm{SH}$ were significantly lower for SY herds (range: 3 to $55 \%$; median $=28.8 \%$ ) compared with herds on concrete flooring (Figure 4); SH prevalence at herd level varied between 10 and $83 \%$ in the P-study (median $=54.1 \%$ ), and 9 and $80 \%$ in the $\mathrm{H}$-study $($ median $=41.2)$.

\section{Influence of Floor System on Claw Disorders}

The influence of floor system on the occurrence of claw disorders is presented in Table 3. Prevalence rates for the examined claw disorders (except IP) are given, as well as OR and associated $P$ values. The small number of IP cases we found is due to the fact that claw health was assessed in a cross-sectional study; IP is acute by nature, and its symptoms are short-lived when immediate treatment is practiced. Before analyzing, the ordinally scored prevalence rates for IDHE, DD, and

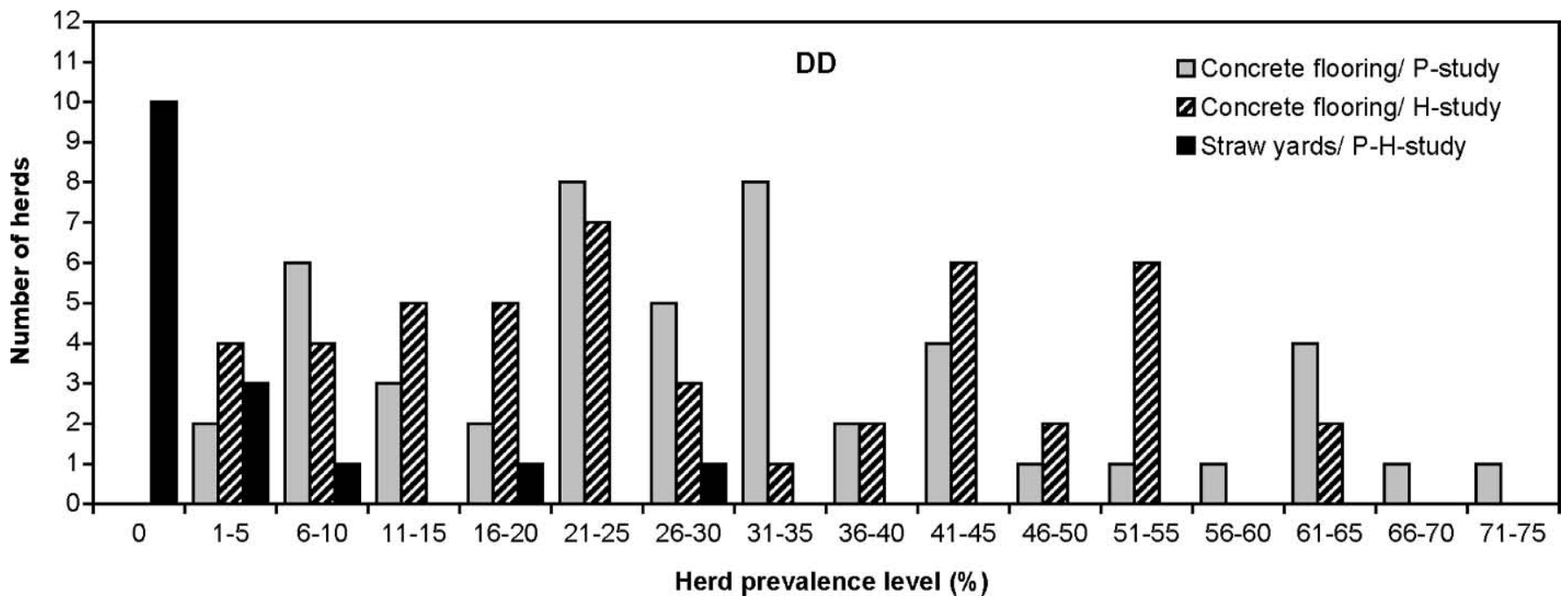

Figure 3. Distribution of herd prevalence rates for digital dermatitis (DD) in Dutch dairy cows exposed to concrete flooring in the P(pasture period 1999; $\mathrm{n}=49$ farms) and $\mathrm{H}$-study (housing period 2000; $\mathrm{n}=47$ farms), and exposed to straw yards in the P/H-study (pasture 1999 + housing $2000 ; n=16$ farms). 
SH (Table 2) were reduced into dichotomous data. An important consideration in the dichotomization was the question to what extent a certain disease stage may result in negative effects on the well-being of a cow. In our opinion, slight, superficial IDHE (grade 1) causes mild inconvenience to a cow. This in contrast to more serious stages of heel erosion (IDHE grades 2 and 3), where deep clefts in the heel and bulb region result in deformation of the claw (Peterse, 1980). As a result, hoof overgrowth is induced in the affected claw, which disturbs the natural weight-bearing process within the claw (overburdening; Toussaint Raven, 1973), and subsequently may affect the locomotion pattern of a cow. Reduction of ordinal scores for DD and SH into binary scores was based on the same well-being considerations, resulting in classifying DD grades 1 and 2 , and $\mathrm{SH}$ grades $1,2,3$, and 4 as DD- and SH-positive, respectively.

$\boldsymbol{S L}$. SL was chosen as the reference floor system.

SL-SCR. Cows exposed to SL-SCR showed lower prevalence rates for infectious claw lesions (e.g. IDHE, $\mathrm{DD}$, and HYP) than cows on SL (Table 3). Also, for the estimated OR for IDHE, DD, and HYP in the P- and $\mathrm{H}$-study (ranging mainly between 0.5 and 0.7 ), a certain potential benefit of the SL-SCR is indicated, though statistical significance is lacking. Wet floor conditions are associated with a higher overall lameness prevalence in US dairy herds (Wells et al., 1995, 1999), and a higher IDHE (Thysen, 1987) and DD incidence (Rodriguez-Lainz et al., 1996) in particular, the use of a manure scraper may reduce these negative effects.

SCF. Thysen (1987) demonstrated that severe IDHE and SUL were more prevalent on SCF than on SL.
These observations were partially confirmed in our survey, since cows kept on SCF tended $(P=0.11)$ to have higher odds for IDHE lesions (OR = 1.7) in the P-study, and SUL $(\mathrm{OR}=1.8)$ in the $\mathrm{H}$-study than cows kept on SL. No other differences in prevalence rates could be determined between cows exposed to on SCF and SL.

$\boldsymbol{Z G}$. In a similar observational field study in 34 Dutch zero-grazing dairies, Smits et al. (1992) reported higher prevalence of IDHE, DD, HYP, and WLA in ZG cows compared with cows at pasture. Our results in the Pstudy are consistent with this report. Compared to cows on SL, cows in ZG herds in the P-study had a significantly $(P<0.01)$ higher odds for IDHE (OR $=2.6)$, DD $(\mathrm{OR}=2.3), \mathrm{SH}(\mathrm{OR}=2.1), \mathrm{SUL}(\mathrm{OR}=2.3)$, and HYP $(\mathrm{OR}=2.3)$. It is noted that, especially in the P-study, the level of exposure to some risk factors differs between ZG cows and cows with grazing facilities. In the $\mathrm{H}-$ study, only HYP $(\mathrm{OR}=2.7)$ was significantly more prevalent, whereas SUL and WLA tended $(P=0.11$; OR $=$ 1.8 ) to be more prevalent in ZG than in SL cows. Moreover, significantly less $\mathrm{SH}(\mathrm{OR}=0.5)$ and $\mathrm{SOC}(\mathrm{OR}=$ 0.4 ) were found.

In contrast to cows exposed to concrete floor systems with grazing (SL, SL-SCR, SCF), overall prevalence rates in ZG cows were similar (IDHE, HYP) or higher (DD, SH, SOC, SUL) in the P- than in the H-study. A possible explanation for the difference in prevalence rates between the $\mathrm{P}$ - and $\mathrm{H}$-study in $\mathrm{ZG}$ cows could be a difference in study population between both seasons. All eight ZG herds included in the P-study were also part of the ZG study population in the H-study $(\mathrm{n}=13$ herds). An additional analysis is presented in Table 4 which illustrates that prevalence rates for DD and HYP

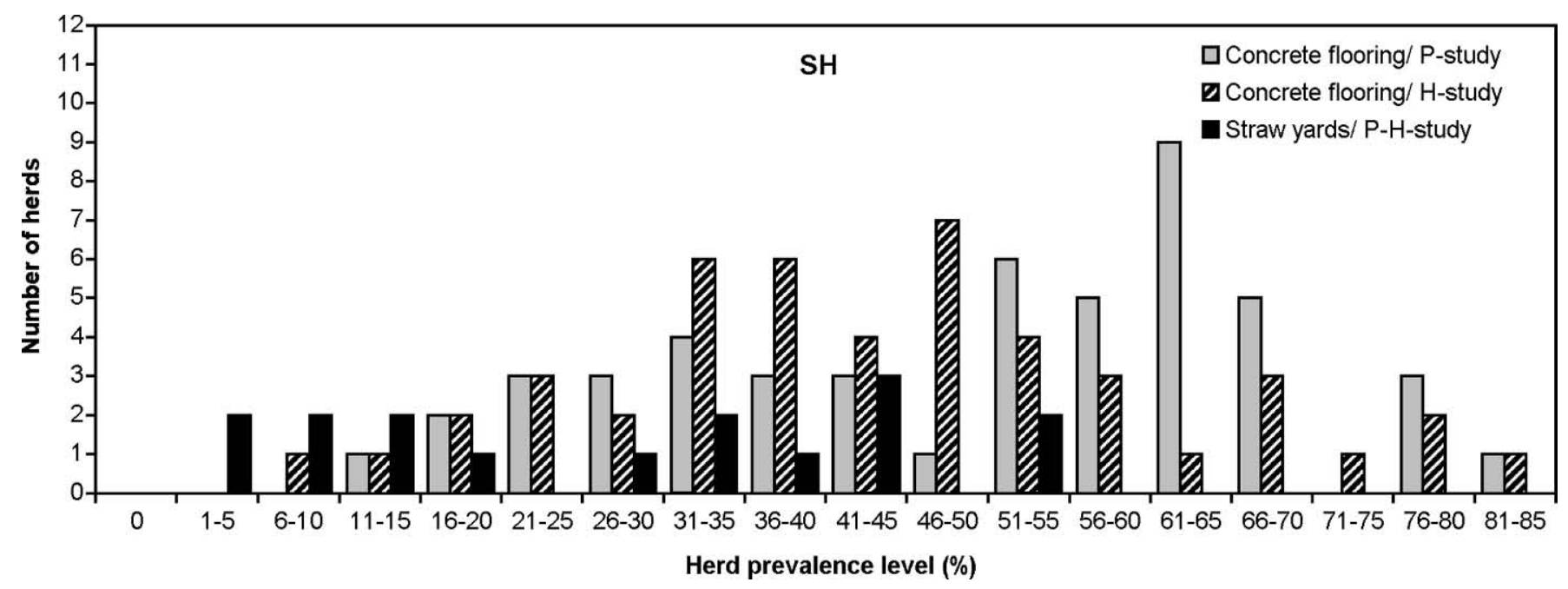

Figure 4. Distribution of herd prevalence rates for sole hemorrhages ( $\mathrm{SH}$ ) in Dutch dairy cows exposed to concrete flooring in the P(pasture period 1999; $\mathrm{n}=49$ farms) and $\mathrm{H}$-study (housing period 2000; $\mathrm{n}=47$ farms), and exposed to straw yards in the P/H-study (pasture 1999 + housing $2000 ; \mathrm{n}=16$ farms). 
Table 3. Analysis of the association between floor system and the presence of a claw disorder (dichotomous outcome) in the P- (pasture period 1999) and H-study (housing period 2000); bold figures give the significant difference with slatted floor (SL $=$ reference floor system) at the level of $P<0.05$. (IDHE = interdigital dermatitis/heel erosion; $\mathrm{DD}=$ dermatitis digitalis; $\mathrm{SH}=$ sole hemorrhages; $\mathrm{SOC}=$ solar contusion; $\mathrm{SUL}=$ sole ulcer; WLS = white line separation; WLA = white line abscess; HYP = interdigital hyperplasia; IP = interdigital phlegmon; SL-SCR = slatted floor with manure scraper; SCF = solid concrete floor; ZG = zerograzing; SY = straw yard).

\begin{tabular}{|c|c|c|c|c|c|c|c|}
\hline \multirow[b]{2}{*}{ Diagnosis } & \multirow[b]{2}{*}{ Floor system } & \multicolumn{3}{|c|}{ P-study } & \multicolumn{3}{|c|}{ H-study } \\
\hline & & Prevalence $^{1}$ & OR & $P$ value & Prevalence & OR & $P$ value \\
\hline \multirow[t]{5}{*}{ IDHE } & SL & 20.7 & Ref. $^{2}$ & - & 50.7 & Ref. $^{2}$ & - \\
\hline & SL-SCR & 14.7 & 0.66 & 0.415 & 35.9 & 0.54 & 0.059 \\
\hline & SCF & 30.4 & 1.67 & 0.106 & 52.4 & 1.07 & 0.829 \\
\hline & $\mathrm{ZG}$ & 40.3 & 2.59 & 0.003 & 42.7 & 0.72 & 0.226 \\
\hline & $\mathrm{SY}^{3}$ & 13.3 & 0.59 & 0.209 & 13.3 & 0.15 & 0.000 \\
\hline \multirow[t]{5}{*}{$\mathrm{DD}$} & $\mathrm{SL}$ & 29.7 & Ref. $^{2}$ & - & 30.8 & Ref. $^{2}$ & - \\
\hline & SL-SCR & 27.5 & 0.90 & 0.795 & 20.1 & 0.57 & 0.155 \\
\hline & SCF & 25.4 & 0.81 & 0.483 & 31.2 & 1.02 & 0.952 \\
\hline & $\mathrm{ZG}$ & 49.0 & 2.28 & 0.006 & 30.7 & 1.00 & 0.993 \\
\hline & $\mathrm{SY}^{3}$ & 3.9 & 0.10 & 0.000 & 3.9 & 0.09 & 0.000 \\
\hline \multirow[t]{5}{*}{$\mathrm{SH}$} & $\mathrm{SL}$ & 45.1 & Ref. $^{2}$ & - & 47.7 & Ref. $^{2}$ & - \\
\hline & SL-SCR & 47.8 & 1.11 & 0.738 & 55.7 & 1.38 & 0.233 \\
\hline & $\mathrm{SCF}$ & 47.0 & 1.08 & 0.753 & 45.2 & 0.91 & 0.720 \\
\hline & $Z G$ & 63.2 & 2.10 & 0.005 & 31.2 & 0.50 & 0.003 \\
\hline & $\mathrm{SY}^{3}$ & 24.3 & 0.39 & 0.002 & 24.3 & 0.47 & 0.006 \\
\hline \multirow[t]{5}{*}{$\mathrm{SOC}$} & $\mathrm{SL}$ & 11.0 & Ref. $^{2}$ & - & 7.2 & Ref. $^{2}$ & - \\
\hline & SL-SCR & 12.8 & 1.18 & 0.600 & 6.5 & 0.91 & 0.784 \\
\hline & $\mathrm{SCF}$ & 11.1 & 1.01 & 0.979 & 10.1 & 1.44 & 0.265 \\
\hline & $Z G$ & 11.3 & 1.03 & 0.921 & 2.9 & 0.39 & 0.013 \\
\hline & $\mathrm{SY}^{3}$ & 5.0 & 0.41 & 0.014 & 5.0 & 0.66 & 0.286 \\
\hline \multirow[t]{5}{*}{ SUL } & SL & 3.3 & Ref. $^{2}$ & - & 3.2 & Ref. $^{2}$ & - \\
\hline & SL-SCR & 3.3 & 1.01 & 0.990 & 2.5 & 0.78 & 0.594 \\
\hline & $\mathrm{SCF}$ & 4.3 & 1.32 & 0.385 & 5.8 & 1.83 & 0.114 \\
\hline & $\mathrm{ZG}$ & 7.4 & 2.34 & 0.005 & 5.2 & 1.64 & 0.146 \\
\hline & $\mathrm{SY}^{3}$ & 2.4 & 0.70 & 0.406 & 2.4 & 0.72 & 0.496 \\
\hline \multirow[t]{5}{*}{ WLS } & $\mathrm{SL}$ & 6.0 & Ref. $^{2}$ & - & 7.0 & Ref. $^{2}$ & - \\
\hline & SL-SCR & 4.2 & 0.68 & 0.549 & 8.7 & 1.28 & 0.591 \\
\hline & SCF & 5.7 & 0.95 & 0.901 & 7.4 & 1.06 & 0.903 \\
\hline & $\mathrm{ZG}$ & 7.6 & 1.28 & 0.549 & 10.6 & 1.58 & 0.225 \\
\hline & $\mathrm{SY}^{3}$ & 26.0 & 5.51 & 0.000 & 26.0 & 4.70 & 0.000 \\
\hline \multirow[t]{5}{*}{ WLA } & $\mathrm{SL}$ & 3.1 & Ref. $^{2}$ & - & 1.4 & Ref. $^{2}$ & - \\
\hline & SL-SCR & 2.8 & 0.91 & 0.834 & 1.2 & 0.84 & 0.748 \\
\hline & $\mathrm{SCF}$ & 2.3 & 0.74 & 0.405 & 0.7 & 0.51 & 0.307 \\
\hline & $\mathrm{ZG}$ & 4.0 & 1.32 & 0.382 & 2.5 & 1.84 & 0.114 \\
\hline & $\mathrm{SY}^{3}$ & 0.8 & 0.25 & 0.021 & 0.8 & 0.56 & 0.335 \\
\hline \multirow[t]{5}{*}{ HYP } & SL & 5.1 & Ref. $^{2}$ & - & 4.3 & Ref. $^{2}$ & - \\
\hline & SL-SCR & 3.3 & 0.64 & 0.352 & 3.0 & 0.70 & 0.401 \\
\hline & $\mathrm{SCF}$ & 6.1 & 1.20 & 0.534 & 5.8 & 1.36 & 0.398 \\
\hline & $Z G$ & 11.1 & 2.33 & 0.002 & 10.8 & 2.70 & 0.000 \\
\hline & $\mathrm{SY}^{3}$ & 1.1 & 0.21 & 0.008 & 1.1 & 0.25 & 0.024 \\
\hline \multirow[t]{5}{*}{$\mathrm{IP}^{*}$} & SL & $2^{* * *}$ & & & $0^{* * * *}$ & & \\
\hline & SL-SCR & 0 & & & 0 & & \\
\hline & SCF & 1 & & & 4 & & \\
\hline & ZG & 3 & & & 4 & & \\
\hline & $\mathrm{SY}^{3}$ & 0 & & & 0 & & \\
\hline
\end{tabular}

*Insufficient cases for statistical analysis.

**Number of cases.

${ }^{1}$ Prevalence based on dichotomous outcomes .

${ }^{2}$ Reference floor system.

${ }^{3} \mathrm{SY}$ farms coming from merged $\mathrm{P} / \mathrm{H}$-study

were significantly higher $(P<0.01)$ in the group of eight $\mathrm{ZG}$ herds (groups $\mathrm{P}$ and $\mathrm{H}$ ) compared with five $\mathrm{ZG}$ herds that were additionally included in the $\mathrm{H}$-study (group H). However, prevalence rates for IDHE, SH, SUL, SOC, and IP in the H-study did not structurally differ between those two groups, suggesting that differences in ZG-study population only partially account for the lower prevalence rates observed in $\mathrm{ZG}$ herds in the $\mathrm{H}$ study. In Table 5, changes in prevalence rates are tested within a group of $536 \mathrm{ZG}$ cows that were included in 
Table 4. Analysis of differences in cow prevalence rates in the $\mathrm{H}$-study between two groups of zero-grazing (ZG) herds; groups $\mathrm{P}$ and $\mathrm{H}$ contain eight ZG herds included in both the P- (pasture period 1999) and Hstudy (housing period 2000); group H contains five ZG herds included in the H-study only; bold figures give the significant difference at $P<0.05$. (IDHE $=$ interdigital dermatitis/heel erosion; $\mathrm{DD}=$ dermatitis digitalis; $\mathrm{SH}=$ sole hemorrhages; $\mathrm{SOC}=$ solar contusion; $\mathrm{SUL}=$ sole ulcer; WLS $=$ white line separation; WLA = white line abscess; HYP = interdigital hyperplasia; IP = interdigital phlegmon).

\begin{tabular}{lllll}
\hline \multirow{2}{*}{$\begin{array}{l}\text { Claw } \\
\text { disorder }\end{array}$} & \multicolumn{2}{c}{ Prevalence rate $^{1}$} & & $\begin{array}{l}\text { Difference } \\
\text { between the groups }\end{array}$ \\
\cline { 2 - 3 } & Groups P and H & Group H & & $\begin{array}{l}\text { Mann-Whitney U } \\
\text { test }\end{array}$ \\
\hline IDHE & 42.8 & 42.6 & +0.2 & 0.954 \\
DD & 37.4 & 19.8 & +17.6 & $\mathbf{0 . 0 0 0}$ \\
SH & 29.8 & 33.3 & -3.5 & 0.219 \\
SOC & 3.2 & 2.4 & +0.8 & 0.404 \\
SUL & 4.8 & 5.7 & -0.9 & 0.546 \\
WLS & 10.3 & 2.1 & -0.8 & 0.662 \\
WLA & 2.5 & 6.1 & +0.1 & 0.915 \\
HYP & 13.7 & 0.2 & +7.6 & $\mathbf{0 . 0 0 0}$ \\
IP & 0.4 & +0.2 & 0.583 \\
\hline
\end{tabular}

${ }^{1}$ Prevalence rate at cow level; based on dichotomous outcome.

both the $\mathrm{P}$ - and $\mathrm{H}$-study. It shows that prevalence rates for DD, SH, and SOC decreased significantly $(P<0.001)$ between the $\mathrm{P}$ - and $\mathrm{H}$-study, whereas HYP significantly increased $(P<0.001)$. Because housing conditions and cow factors (except for a 6-mo increase in age) remain unchanged throughout this period in ZG herds, other farm factors (e.g., management routines, feeding rationing) may play a role in the occurrence of these claw disorders.

SY. As with other studies (Maton et al., 1987; Murphy et al., 1987; Vaarst et al., 1998), we recorded more claw lesions in dairy cattle exposed to SL than to SY. Cows kept in SY showed significantly less DD ( $\mathrm{OR}=0.1), \mathrm{SH}$ $(\mathrm{OR}=0.4)$, SOC $(\mathrm{OR}=0.4)$, WLA $(\mathrm{OR}=0.3)$, and HYP $(\mathrm{OR}=0.2)$ than cows exposed to $\mathrm{SL}$ in the P-study. Compared to cows on SL in the H-study, less IDHE (OR $=0.2), \mathrm{DD}(\mathrm{OR}=0.1), \mathrm{SH}(\mathrm{OR}=0.5)$, and HYP $(\mathrm{OR}=$ $0.3)$ was observed in cows kept in SY. Conversely, cows in SY had a 5.5- and 4.7-times higher risk (odds) for
WLS than cows on SL in the P- and H-study, respectively. We are unaware of published research that reports similar prevalence rates for WLS in SY systems. In our study, bias in WLS prevalence rate may have appeared by introducing the group of seven SY herds that did not regularly trim their cows. It appeared that in this group the prevalence rate for WLS was higher than among the remaining cows in SY ( 49.8 vs. $8.9 \%$, respectively; $P<0.001$ ). Due to the lack of preventive hoof trimming, excessive hoof growth can occur (Vermunt and Greenough, 1995), and subsequently result in overloading at specific regions of the hind lateral claw (Toussaint Raven, 1985). Another possible explanation is the fact that most cows in SY systems have to mount small concrete stair(s) several times a day when they go from the straw bedded area to the feeding rack or milking yard. It is possible that during mounting those steps, the white line area in the hoof is exposed

Table 5. Analysis of differences in cow prevalence rates between the P-and H-study using 536 zero-grazing cows that were included in both the P- (pasture period 1999) and H-study (housing period 2000); bold figures give the significant difference at $P<0.05$. (IDHE $=$ interdigital dermatitis/heel erosion; $\mathrm{DD}=$ dermatitis digitalis; $\mathrm{SH}=$ sole hemorrhages; $\mathrm{SOC}=$ solar contusion; $\mathrm{SUL}=$ sole ulcer; WLS = white line separation; WLA = white line abscess; HYP = interdigital hyperplasia; IP = interdigital phlegmon).

\begin{tabular}{lcccc}
\hline \multirow{2}{*}{$\begin{array}{l}\text { Claw } \\
\text { disorder }\end{array}$} & Prevalence rate & & $\begin{array}{c}\text { Difference } \\
\text { between the groups }\end{array}$ & $\begin{array}{l}\text { Wilcoxon Signed } \\
\text { Ranks test }\end{array}$ \\
\cline { 2 - 4 } & P-study & H-study & -1.7 & 0.494 \\
IDHE & 41.8 & 43.5 & +9.1 & $\mathbf{0 . 0 0 0}$ \\
DD & 45.1 & 36.0 & +38.3 & $\mathbf{0 . 0 0 0}$ \\
SH & 64.4 & 26.1 & +7.4 & $\mathbf{0 . 0 0 0}$ \\
SOC & 10.8 & 3.4 & +1.5 & 0.217 \\
SUL & 6.5 & 11.8 & -3.4 & 0.052 \\
WLS & 8.4 & 2.6 & +0.4 & 0.715 \\
WLA & 3.0 & 14.2 & -5.2 & $\mathbf{0 . 0 0 0}$ \\
HYP & 9.0 & 0.4 & 0.0 & 1.000 \\
IP & 0.4 & &
\end{tabular}

${ }^{1}$ Prevalence rate at cow level; based on dichotomous outcome. 
to extra forces to such an extent that traumatic damages in the white line area result.

\section{Impact of Claw Disorders}

Welfare is an important issue with respect to lameness in dairy cows. Together with mastitis, lameness is recognized the most important health problem having a negative effect on the welfare of dairy cows (Webster, 1987; Alban, 1995; Albright, 1995). The degree of lameness depends on the severity of the pathology and is a direct result of pain on weight-bearing (Weaver, 2000). In pursuit of a sound welfare indicator, Manson and Leaver (1988) have developed locomotion score as a simple and objective tool of monitoring clinical lameness. However, the impact of subclinical lameness, e.g., the level of claw disorders, is underestimated in this method. In our study, we found that, on average $80 \%$, of the cows exposed to concrete flooring were affected by one or more claw disorders at the same time. This high level of claw lesions has negative consequences for both animal welfare and economics. Animals may suffer from subclinical affections for a long time, as some disorders are long-lasting and painful (Alban, 1995). Even after hoof trimming and any subsequent therapy, some disorders with a chronic course (e.g., DD, SUL) may hinder cows for a long period in their normal activity pattern, locomotion, and social behavior. Further research is needed to clarify more specifically the negative effects of different levels of subclinical lameness on animal welfare. In addition, research is necessary to explore the applicability of local soft surface areas in traditional concrete flooring systems. In this way, claw health most likely can be improved in dairy cows kept in cubicle loose housing systems.

\section{CONCLUSIONS}

The majority of cows had claw disorders at subclinical level. Many cows exposed to concrete flooring had one or two claw disorders at the same time. Cows housed in SY systems had the lowest levels of claw disorders, a marked contrast to concrete flooring. Within the studied concrete floor systems, we found some differences in claw health. In infectious claw disorders (IDHE, DD, HYP), SL-SCR indicated some beneficial effect, but more research is needed to quantify the findings further. The high prevalence rates found in $\mathrm{ZG}$ cows in the P-study argue in favor of grazing facilities during the summer.

\section{ACKNOWLEDGMENTS}

The authors thank the participating dairy farmers and families for their cooperation and hospitality. In addition, we acknowledge Jasper Blok, Joost van Egmond, Annelieke Steenbergen, Tineke Wassenaar, and Dirk-Jan Willemsen for their assistance in recording claw health. The Dutch Technology Foundation (STW) and the Ministry of Agriculture funded this project.

\section{REFERENCES}

ADAS. 1994. The design of dairy cow housing. CIGR Section II: Working Group Cattle Housing, ADAS, Winchester, United Kingdom.

Alban, L. 1995. Lameness in Danish dairy cows; frequency and possible risk factors. Prev. Vet. Med. 22:213-225.

Albright, J. C. 1995. Flooring in dairy cattle facilities. Pages 168182 in Proc. Int. Conf. Anim. Behav. Design. Livest. Poult. Syst., Indianapolis, IN

Braam, C. R., and D. Swierstra. 1997. Developments in design of concrete floors in dairy cattle houses; impact of environmental demands. Pages 11-22 in Proc. Concr. for a Sustain. Agric., Stavanger, Norway.

Bergsten, C. 1995. Digital disorders in dairy cattle with special reference to laminitis and heel horn erosion: the influence of housing, managemen, and nutrition. Ph.D. Diss., Swedish Univ. of Agriculture Sciences, Skara, Sweden.

CBS. 2000. Agricultural Census 2000. Statistics Netherlands, ed. Elsevier, Voorburg, The Netherlands.

Clarkson, M. J., D. Y. Downham, W. B. Faull, J. W. Hughes, F. J. Manson, J. D. Merrit, R. D. Murray, W. B. Russell, J. E. Sutherst, and W. R. Ward. 1993. An epidemiological study to determine the risk factors of lameness in dairy cows. CSA 1379, Univ. Liverpool, United Kingdom.

Döpfer, D. 1994. Epidemiological investigations about digital dermatitis on two dairy farms. Ph.D. Diss., Tierärztliche Hochschule, Hannover, Germany.

Enevoldsen, C., and, Y. T. Gröhn. 1991. Sole ulcers in dairy cattle: associations with season, cow characteristics, disease, and production. J. Dairy Sci. 74:1284-1298.

Farm Animal Welfare Council. 1997. Report on the Welfare of Dairy Cattle. FAWC. Tolworth, United Kindom.

Faye, B., and F. Lescourret. 1989. Environmental factors associated with lameness in dairy cattle. Prev. Vet. Med. 7:267-287.

Frankena, K., E. N. Stassen, J. P. Noordhuizen, J. O. Goelema, J. Schipper, H. Smelt, and H. Romkema. 1991. Prevalence of lameness and risk indicators for dermatitis digitalis during pasturing and housing of dairy cattle. Pages 107-118 in Proc. Ann. Symp. Soc. Vet. Epidemiol. Prev. Med., London, United Kingdom.

Frankena, K., K. A. S. van Keulen, J. P. Noordhuizen, E. N. Noordhuizen-Stassen, J. Gundelach, D. J. de Jong, and I. Saedt. 1993. A cross-sectional study into prevalence and risk factors of dermatitis interdigitalis in female dairy calves in the Netherlands. Prev. Vet. Med. 17:137-144.

Fregonesi. J. A., 1999. Production and behavior of dairy cattle in different housing systems. Ph.D. Diss., Univ. London, United Kingdom.

Fregonesi. J. A., and J. D. Leaver. 2000. Behavior, performance, and health indicators of welfare for dairy cows housed in strawyard or cubicle systems. Livest. Prod. Sci. 68:205-216.

Gitau, T., J. J. McDermott, and S. M. Mbiuki. 1996. Prevalence, incidence, and risk factors for lameness in dairy cattle in smallscale farms in Kikuyu Divison, Kenya. Prev. Vet. Med. 28:101115.

Greenough, P. R., and J. J. Vermunt. 1991. Evaluation of subclinical laminitis in a dairy herd and observations on associated nutritional and management factors. Vet. Rec. 128:11-17.

Gröhn, J. A., J. B. Kaneene, and D. Foster. 1992. Risk factors associated with lameness in lactating dairy cattle in Michigan. Prev. Vet. Med. 14: 77-85.

Hughes, J. W., W. B. Faull, P. J. Cripps, and N. P. French. 1997. Environmental control of bovine lameness. Cattle Practice 5: $235-246$. 
Hultgren, J. 2002. Foot/leg and udder health in relation to housing changes in Swedish dairy herds. Prev. Vet. Med. 53:167-189.

Leaver, J. D. 1988. Management and Welfare of Farm Animals. 3rd ed. Balliere Tindall, London, United Kingdom.

LEI (Agricultural Economics Research Institute), and CBS (Statistics Netherlands), 2001. Agri- and Horticulture Statistics 2001 (in Dutch). The Hague, The Netherlands.

Livesey, C. T., T. Harrington, A. M. Johnston, S. A. May, and J. A. Metcalf. 1998. The effect of diet and housing on the development of sole haemorrhages, white line haemorrhages, and heel erosions in Holstein heifers. Anim. Sci. 67:9-16.

Manson, F. J., and J. D. Leaver. 1998. The influence of concentrate amount on locomotion and clinical lameness in dairy cattle. Anim. Prod. 47:185-190.

Maton, A. 1987. The influence of the housing system on claw disorders with dairy cows. Pages 151-158 in Cattle Housing Systems, Lameness and Behavior. Martinus Nijhoff Publishers, Dordrecht, The Netherlands.

Murphy, P. A., J. Hannan, and M. Monaghan. 1987. A survey of lameness in beef cattle housed on slats and on straw. Pages 6772 in Cattle Housing Systems, Lameness, and Behavior. Martinus Nijhoff Publishers, Dordrecht, The Netherlands.

Peterse, D. J. 1980. Judgement of bovine claws by the occurrence of sole lesions. Ph.D. Diss., State Univ., Utrecht, The Netherlands.

Peterse, D. J. 1985. Breeding. Pages 121-123 in Cattle Footcare and Claw Trimming. Ed. Farming Press, Ltd., Ipswich. United Kingdom.

Peterse, D. J., 1987. Aetiology of claw disorders in dairy cattle. Pages 3-7 in Cattle Housing Systems, Lameness, and Behavior. Ed. Martinus Nijhoff Publishers, Dordrecht, The Netherlands.

RDA (Dutch Advisory Board for Animal Welfare \& Health Affairs). 1996. Inventory of targets for housing and management of cattle from an age of 6 mo onwards (in Dutch). The Hague, The Netherlands.

Read, D. H., D. L. Walker, A. E. Castro, J. P. Sundberg, and M. C. Thurmond. 1992. An invasive spirochete associated with interdigital papillomatosis of dairy cattle. Vet. Rec. 130:59-60.

Read, D. H., and D. L. Walker. 1998. Papillomatous digital dermatitis (footwarts) in California dairy cattle: clinical and gross pathologic findings. J. Vet. Diagn. Invest. 10: 67-76.

Rodriguez-Lainz, A., D. W. Hird, T. E. Carpenter, and D. H. Read. 1996. Case-control study of papillomatous digital dermatitis in southern California dairy farms. Prev. Vet. Med. 28:117-131.

SAS User's Guide: Statistics, Version 6.12, 1996. SAS Inst., Inc., Cary, NC.
Singh, S. S., W. R. Ward, J. W. Hughes, K. Lautenbach, and R. D. Murray. 1994. Behavior of dairy cows in a straw yard in relation to lameness. Vet. Rec. 135:251-253.

Smits, M. J. C., K. Frankena, J. H. M. Metz, and J. P. T. M. Noordhuizen. 1992. Prevalence of digital disorders in zero-grazing dairy cows. Livest. Prod. Sci. 32:231-244.

SPSS, 2002. User's Guide: Statistics, Version 11.0.1. SPSS, Inc., Chicago, IL.

Thrusfield, M. V. 1986. Veterinary Epidemiology. Butterworth \& Co., Ltd., London, United Kingdom.

Thysen, I. 1987. Foot and leg disorders in dairy cattle in different housing systems. Pages 166-178 in Cattle Housing Systems, Lameness, and Behavior. Martinus Nijhoff Publishers, Dordrecht, The Netherlands.

Toussaint Raven, E. 1973. Determination of weight-bearing by the bovine foot. Neth. J. Vet. Sci. 5:99-103.

Toussaint Raven, E. 1985. Cattle Footcare and Claw Trimming. Farming Press, Ltd., Ipswich. United Kingdom.

Vaarst, M., J. Hindhede, and C. Enevoldsen 1998. Sole disorders in conventionally managed and organic dairy herds using different housing systems. J. Dairy Res. 65:175-186.

Vermunt, J., and P. R. Greenough. 1995. Structural characteristics of the bovine claw: horn growth and wear, horn hardness and conformations. Br. Vet. J. 151:157-180

Vermunt, J., and P. R. Greenough. 1996. Sole haemorrhages in dairy heifers managed under different underfoot and environmental conditions. Brit. Vet. J. 152:57-73.

Vokey, F. J., C. L. Guard, H. N. Erb, and D. M. Galton. 2001. Effects of alley and stall surfaces on indices of claw and leg health in dairy cattle housed in a free-stall barn. J. Dairy Sci. 84:2686-2699.

Weaver, A. D. 2000. Lameness. Pages 149-202 in The Health of Dairy Cattle. A.H. Andrews, ed. Blackwell Science, Oxford, United Kingdom.

Webster, J. 1987. Understanding the Dairy Cow. Pages 219-227. BSP Professional Books, Oxford, United Kingdom.

Webster, J. 1995. Animal Welfare: a Cool Eye towards Eden: a Constructive Approach to the Problem of Man's Domination over Animals. Blackwell Science, Oxford, United Kingdom.

Wells, S. J., A. M. Trent, W. E. Marsch, N. B. Williamson, and R. A Robinson. 1995. Some risk factors associated with clinical lameness in dairy herds in Minnesota and Wisconsin. Vet. Rec. 136:537-540.

Wells, S. J., L. P. Garber, and B. A. Wagner. 1999. Papillomatous digital dermatitis and associated risk factors in US dairy herds. Prev. Vet. Med. 38:11-24. 